Euskal ikerketen aldizkaria | Revue d'études basques |

Revista de estudios vascos | Basque studies review

$20 \mid 2017$

Numéro $X X$

\title{
Ene eta neure Etxepareren Linguae Vasconum
}

\section{Primitiae-an}

\section{Mikel Martínez Areta}

\section{OpenEdition}

\section{Journals}

Édition électronique

URL : https://journals.openedition.org/lapurdum/3509

DOI : 10.4000/lapurdum.3509

ISSN : 1965-0655

\section{Éditeur}

IKER

Édition imprimée

Date de publication : 1 janvier 2017

Pagination : 117-130

ISBN : 978-2-95534-135-3

ISSN : $1273-3830$

Référence électronique

Mikel Martínez Areta, «Ene eta neure Etxepareren Linguae Vasconum Primitiae-an», Lapurdum [Linean], 20 | 2017, Sarean emana----an 01 janvier 2021, kontsultatu 03 septembre 2021. URL: http:// journals.openedition.org/lapurdum/3509; DOI: https://doi.org/10.4000/lapurdum.3509 


\title{
Ene eta neure
}

\section{Etxepareren Linguae Vasconum Primitiae-an ${ }^{1}$}

\author{
Mikel MARTÍNEZ ARETA \\ Euskal Herriko Unibertsitatea (UPV/EHU)
}

\section{Sarrera}

Martínez Areta 2015-en Linschmann-Aresti legea (hemendik aurrera, = LA legea ${ }^{2}$ ) Lazarragaren eskuizkribuan nola eta zein neurritan betetzen den arakatzeko baliatu dudan prozedura berari jarraikiz, artikulu honetan azterketa bera Etxepareren Linguae Vasconum Primitiae-arekin egitea dut helburu. Arazoak, noski, bestelakoak dira, eta, zehaztuko diren arrazoiengatik, interesa kasik zeharo 1. pertsona singularrean gertatzen denera murrizten da. Hortik lan honen izenburua.

Oro har, LA legeari ez ohi zaio arreta handirik eman, ez sintaxilarien aldetik ez testuparatzaileenetik, agian funtsezko gertakariak argi baitaude, eta bestetik salbuespenak eragin edo baldintza ditzaketen faktoreak maiz gure ulermena irits daitekeenaz haraindi daudela uste baitugu. Jarrera hau ulergarria bada ere, euskal hizkuntzalaritza diakronikoak azken urteotan izan dituen aurrerapenen argitan galdera zahar batzuk berriro eztabaidatzea merezi duelakoan nago.

1. Lan honek hiru ikerketa proiekturen laguntza jaso du: 1) "Monumenta Linguae Vasconum IV: historia,crítica y edición de textos vascos" [= FFI2012-37696], Joseba Lakarrak zuzendua eta Espainiar Gobernuko Hezkuntza eta Zientzia Ministerioak finantzatua; 2) "Historia de la Lengua Vasca y Lingüística Histórico-Comparada" (HLMV-LHC), Ref. GIC 10/83, IT 486-10, Joaquín Gorrochateguik zuzendua eta Eusko Jaurlaritzak finantzatua; eta 3) "Hizkuntzalaritza Teorikoa eta Diakronikoa: Gramatika Unibertsala, Hizkuntza Indoeuroparrak eta Euskara" Heziketa eta Ikerkuntza Unitatea (UFI 11/14), Euskal Herriko Unibertsitateak finantzatua. Eskerrak eman nahi dizkiot Borja Ariztimuñori, testuari buruzko zenbait ohar egiteagatik, eta orokorrean Linschmann-Aresti legeari buruz izan ditugun eztabaida mamitsuengatik. Akatsak nireak dira.

2. Laburdurak: LA legea = Linschamnn-Aresti legea; EBZ = Euskara Batu Zaharra; LVP = LinguaeVasconum Primitiae; IS = Izen Sintagma. 


\section{LA legea Etxepareren LVP-an, eta hura arakatzeko irizpideak}

\subsection{LA legea Etxepareren LVP-an}

LA legeak Etxepareren Linguae Vasconum Primitiae-an agertzen dituen berezitasunak orokorrean ez dira asko, eta Rebuschik 1995: 343-347 bikain laburbildu zituen. Legea oro har betetzen da, baina, Leizarragagan eta autore zuberotarrengan bezala, gure-/geure-, zure-/zeure-, zuen-/zeuen- bikoteetan aldaera indartuak desagertu dira eta neutroak (gure-, zure-, zuen-) testuinguru guztietara hedatu. 3. pertsonan, ordea, legea bikain mantentzen da, eztabaidatuko dugun kasuren bat gorabehera, eta lagunarteko tratamenduko 2. pertsona singularrean ere bai, salbuespenik gabe, gainontzeko autoreengan bezalaxe marka alokutiboek aldaera indartua baimentzen ez dutela zehazturik.

\subsection{LA legea aztertzeko irizpideak, eta legearen inguruko zenbait gogoeta}

Lazarragaren eskuizkribua aztertzeko erabili nituen berberak izango dira (ikus Martínez Areta 2015: 458-459). LVP-ko genitibozko izenordain guztiak (zentzu zabalean, hala ene (izenian) bezalako izenlagunak nola harekila bezalako genitibozko izenordainetatik eratorritako adizlagunak) lau agerpen-motatako batean sartuko dira, 1. taulan: n. (neutroa, LA legea betetzen da), i. (indartua, LA legea betetzen da), n. > i. (LA legea ez da betetzen), i. > n. (LA legea ez da betetzen). Taula berak hiru testuinguru bereiziko ditu: aditz jokatuko perpausak, aditz jokatugabeko perpausak eta aditz isileko perpausak gehi bokatibozko sintagmak (azken biok elkarrekin). Rebuschi 1995-en bezala, legea aztertzeko 3. pertsonak ere aintzat hartuko dira, eta, lan berean bezala, legea beteko da baldin eta genitibozko izenordain indartu baten pertsona dagokion esparru sintaktikoko aditzean — dela jokatua, dela jokatugabea — indexatuta badago (eta alderantziz).

Esparru sintaktiko bakoitza aditz bakoitzaren "menpe" dagoen elementu guztien multzoa izango da. Tesnière-en ildotiko menpekotasun-sintaxiari loturiko esparru batetik abiatuko naiz, beraz, honela erosoenik sentitzen bainaiz esparru sintaktikoak zedarritzeko, genitibozko izenordain bat duen IS bakoitza zein aditzen menpe - hain zuzen- dagoen zehazteko, eta ondorioz LA legea betetzen den egiaztatzeko. Uste dut LA legea komunztadura prozesu bat bezala azter daitekeela. Aditzak parte hartzen duen komunztadura prozesu gehienen alderantzira, baina, komunztaduraren norabidea ez da perpauseko elementu batetik aditzera, aditzetik perpauseko elementura baizik. Aditza dugu, beraz, kontrolatzailea (ing. "controller"), eta genitibozko izenordaina xedea (ing. "target").

Oro har, noiz dugun esparru sintaktiko bat "irradiatzen" duen aditz jokatu(gabe) 
bat ez dit buruhausterik sortu ${ }^{3}$. Esparru sintaktiko etenik (ing. "discontinuous") ere bada, baina hausturak ez dira hortik etorri. Honakoan adibidez, menpeko perpausa nagusiaren gainetik igarotzen da, beronen aditzaren ergatibozko marka erreferentziakideak menpekoaren genitibozko ordainaren aldaera indartua baimentzen (ing. "license") ez duela: [ene ${ }_{-i}$ ustian] eztu-t $t_{-i}$ erran [desonesta den gauzarik] (VIII, 11). ${ }^{4}$

Esku artean duguna 3. pertsona bat denean, perpauseko argumentuak eta aditzeko argumentu-markak erreferentziakideak izan beharko dute. Bestetik, aditz jokatugabeetan, sakoneko argumentuak zeintzuk diren ondorioztatuko da, eta aditz isileko aditzetan zein den isilean geratu den aditza (esan behar dut ez dudala duda-muda handiegirik sortu didan agerpenik topatu). Bokatibozko sintagmei dagokienez, berauen forma esperogarria neutroa delako hipotesitik abiatu naiz, datuak moduren batean sailkatu behar baitira, baina Rebuschiren analisi alternatiboa ere aztertu dut, §4.6-n.

Etxepareren testuak, dena dela, berezitasun garrantzitsu bat agertzen du. Lazarragagan ez bezala, Etxeparegan, eta orokorrean ekialde mutur osoan, datibo komunztaduraren trinkotasunik eza daukagu. Mounolek 2015 arrazoi irmoak eman ditu fenomeno hau berrikuntza ez delako baizik eta eratorpen aplikatiboak aditz-morfologia osora hedatu ez zirelako ikuspegiaren alde. Honek LA legea kasuotan nola arakatuko dugun zehaztera behartzen gaitu. Zer hartu behar dugu aintzat? Perpauseko argumentuak (agerikoak edo ezagerikoak), ala bakarrik aditz jokatuan ageriki azaltzen diren argumentu-markak? Bestela esan, zer egin sententiaz eman dezan iuiak nori beria (I, 269) bezalako kasu baten aurrean? Beste zenbaitek bestelako irizpide bat hartuko luketela jakinik ere, Martínez Areta 2015-en ezarri

3. Adibide konkretu batekin, uste dut ez dela zalantzazkoa Eskaintzako (18-20) igorten darauritzut heuskarazko kopla batzu [ene ignoranziaren araura egin]-ak esaldian egin-ek esparru sintaktiko konkretu bat (kortxeteen bidez markatua) irradiatzen duen aditz jokatugabe bat dela. Egin hori egin diren-ekin ordezka dezakegu, adiera aldatzen ez dela. Diren horretan argumentu bakarra 'haiek' da, eta hortik ene (darauritzut-en menpe balego, ordea, neure espero genuke). Aitzitik, ene unsa eginak ere orai oro gaitz dira; (XIII, 20) esaldiko eginak partizipio bat (hots, izenondo bat) besterik ez da, eta hura menpe duen aditza dira dugu (hortik ene).

4. Hauxe da, behintzat, nire interpretazioa. Ez Altunak ez Rebuschik ez dute iruzkinik egiten, eta esango nuke honek esan nahi duela LA legea betetzen dela uste dutela, nire interpretazioan bezalaxe. Legearen hausturatzat jotzeko, bururatzen zaizkidan azalpen bakarrak lirateke: a) Ene ustian, - koma neuk jarrita, analisi honetarako- mintzagaitzat jotzea, ezker aldeko destokitzearen bidez mintzagaia perpauseko joko morfo-sintaktikotik kanpo geratzen delarik (ikus Martínez Areta 2015: 465-466, honen inguruan); b) Ene ustian esamolde tinko eta aldaezintzat jotzea. Ez batak ez besteak ez dute paralelorik LVP osoan.

5. Izan ere, Etxepareren olerkietan aditz isileko perpausak bereziki ugari dira, esango nuke Lazaragarenetan baino ugarixeago. Isilean gordetzen dena laguntzailea izan daiteke (adibidez, bere irudi propiara gure arima kreatu; I, 3, duien isilean gordetzen dela), edo aditz-sintagma osoa, dela hau trinko bat (graziak oro bere eskuian nahi duien orduian; I, 48, dituela-edo isilean gordetzen dela), dela perifrastiko bat (Prinze eta iaun handiek orok haren galdia; XV, 12, egiten dute isilean gordetzen dela), dela perifrastikoaren bi zati (goiz et'arrats orhituki haren izena laudatu; I, 20, behar dugu isilean gordetzen dela). Hauek guztiok talde berean (aditz isileko perpausetakoan) sartu dira. 
nuen irizpide berari jarraituko natzaio, eta aipaturiko perpausa n. >i. kasuetara joango da 1. taulan.

Zer egin, baina, aurreko kasuetarik aditz laguntzailea isilean gordetzen dutenekin? Hemen perpauseko argumentuek aurresaten duten laguntzailearen argumentuak hartu ditut aintzat, datibo komunztadurarik ez balego bezala, bestela komunztadura zein aditzek saihesten duen eta zeinek ez espekulatzera behartuta nengokeelakoan. Honek arbitrariotasunen batera eraman nau, baina gainerako aukerak okerrago direla uste dut. Adibidez, Ieinkoari han gomenda bere etxe sainduian (I, 26) i. kasuetan sartu dut, isilean gorde den laguntzailea akio 'hakio' delakoan, bost bertso gorago laguntzailea isilean gordetzen ez den agerpen kasik berdin batean honek datibo komunztadura egiten ez badu ere (ikus gomend'adi Ieinkoari; I, 21), I, 26ra estrapolaturik n. > i. kasuetan sartzera behartuko nindukeena.

\$2.1-en esandakoaren arabera, gure-/geure-, zure-/zeure- eta zuen-/zeuen- bereizketak arakatzeak ez dauka zentzurik LA legearen ikuspegitik, indartuak desagertu baitira. Hala ere, genitibozko izenordainetan pertsona bakoitzaren agerpen-maiztasuna edozein kasutan interesgarria izan daitekeelakoan, ez ditut analisitik at utzi, eta tauletan sartu ditut. 1. taulan, metodologia berberari jarraitzeko haietan LA legeak funtzionatuko bailuan aztertu ditut. Hala ere, legearen betetze / hauste kasuen proportzioa ez desitxuratzeko, 2. taulan erabateko zenbaketatik at utzi ditut (hortik ilara horien tatxatua).

\section{Analisiaren datuak}

Aurreko irizpideak kontuan harturik, honakoak ditugu, nire zenbaketaren arabera, LA legeak LVP-an agertzen dituen datuak.

\begin{tabular}{|c|c|c|c|c|c|c|c|c|c|c|c|c|}
\hline & \multicolumn{10}{|c|}{ Aditz jokatuko perpausak } & \multicolumn{3}{l|}{$\begin{array}{l}\text { Aditz } \\
\text { perpausak }\end{array}$} \\
\hline & n. & i. & n. > i. & i. $>$ n. & n. & i. & n. > i. & i. > n. & n. & i. & n. > i. & i. > n. \\
\hline 1.sg. & 31 & 19 & 0 & 5 & 5 & 6 & 0 & 0 & 17 & 4 & 2 & 0 \\
\hline 2.sg.(hi) & 4 & 13 & 0 & 0 & 0 & 0 & 0 & 0 & 1 & 0 & 0 & 0 \\
\hline 3.sg. & 25 & 23 & 2 & 0 & 2 & 5 & 0 & 0 & 15 & 10 & 0 & 1 \\
\hline 1.pl. & 22 & 0 & 0 & 8 & 0 & 0 & 0 & 0 & 2 & 0 & 0 & 3 \\
\hline 2.sg.(zu) & 29 & 0 & 0 & 9 & 6 & 0 & 0 & 0 & 5 & 0 & 0 & 2 \\
\hline 2.pl. & 4 & 0 & 0 & 0 & 0 & 0 & 0 & 0 & 2 & 0 & 0 & 1 \\
\hline 3.pl. & 5 & 6 & 0 & 0 & 0 & 0 & 0 & 0 & 5 & 1 & 0 & 0 \\
\hline & \multicolumn{10}{|c|}{ 1. taula. LA legearen datuak Etxepareren LVP-an } \\
\hline
\end{tabular}


2. taulak LVP-an agertzen den LA legearen betetze / hauste proportzio hutsa darakuskigu, beti ere nire zenbaketaren arabera.

\begin{tabular}{|c|c|c|c|c|c|c|c|c|}
\hline & \multicolumn{2}{|l|}{$\begin{array}{l}\text { Aditz jokatuko } \\
\text { perpausak }\end{array}$} & \multicolumn{2}{l|}{$\begin{array}{l}\text { Aditz jokatugabeko } \\
\text { perpausak }\end{array}$} & \multicolumn{2}{l|}{$\begin{array}{l}\text { Aditz isileko perpausak } \\
\text { eta bokatiboak }\end{array}$} & \multicolumn{3}{|c|}{ Orotara } \\
\hline & Bai & Ez & Bai & Ez & Bai & Ez & Bai & Ez \\
\hline 1.sg. & 50 & 5 & 11 & 0 & 21 & 2 & 82 & 7 \\
\hline 2.sg.(hi) & 17 & 0 & 0 & 0 & 1 & 0 & 18 & 0 \\
\hline 3.sg. & 48 & 2 & 7 & 0 & 25 & 1 & 80 & 3 \\
\hline 7.pl. & $z z$ & 8 & $\theta$ & $\theta$ & $z$ & 3 & $z 4$ & 71 \\
\hline Z.sg.(zu) & $z 9$ & $\theta$ & 6 & $\theta$ & 5 & $z$ & 40 & 71 \\
\hline Z.pl. & 4 & $\theta$ & $\theta$ & $\theta$ & $z$ & 7 & 6 & 7 \\
\hline 3.pl. & 11 & 0 & 0 & 0 & 6 & 0 & 17 & 0 \\
\hline Orotara & 126 & 7 & 18 & 0 & 53 & 3 & 197 & 10 \\
\hline
\end{tabular}

2. taula. LA legearen betetze / hauste kasuak Etxepareren LVP-an

197 / 10 proportzio horretan, 3. p. sg.eko hiru hausturetarik bakarrik bat da "benetakoa" (ikus §4.1). 1. p. sg.ean dauden 7etarik, 2 bokatibozko ISetan ohiko jokaera n. dela interpretatzearen ondorio dira. Baina bokatiboak ohiko sintaxitik geratzen direnez (dena den, ikus §4.6), "benetako" hausturak 5 dira, 5 ak aditz jokatuko perpausetan. Bene-benetako hausturak, beraz, 6 dira, 5 1. p. sg.ean.

\section{Salbuespenen azterketa}

Atal honetan, gaika aztertuko ditut haustura guztiak, §4.1-en 1. p. sg.ekoez beste guztiak (ikusiko den legez, benetako haustura bakarra Esk, 4-koa da), eta gainontzeko azpiataletan 1 p. sg.ekoak. Hauetarako, eman diren aurreko azalpenak gogoratzeaz gain, bestelako hausnarketa batzuk eztabaidaratuko ditut.

\subsection{LA legearen salbuespenak 3. pertsonekin}

Has gaitezen 3. pertsonako salbuespenekin. (la-c) ditugu.

(1) a. Erregeren adbokatu bidezko eta nobleari, birthute eta hon guziez konplituiari, bere iaun eta iabe Bernard Leheteri, Bernard Etxeparekoak, haren zerbitzari xipiak, gogo honez gorainzi, bake eta osagarri (Esk, 1-6)

b. sententiaz eman dezan iuiak nori beria

c. hark orori emanen dik bere merexituia

(XIII, 82) 
\$2.1-en esandakoaren arabera, ( 1 b-c) ez dira benetako salbuespenak, baina harturiko irizpideei jarraikiz n. > i. kasuetan sartu ditut, aditzak ez baitu hari dagokion markarik. Biek ematen dute aditzera perpausean genitibozko izenordainarekin erreferentziakidea den datiboan dagoen ageriko IS batek aldaera indartua baimentzen duela, aditzean datibo komunztadurarik ez izan arren.

(1a), ordea, benetako haustura bat da (etzanetan jarritako formaz ari naiz), 3. pertsonarekin Etxepareren lan osoan gertatzen den bakarra, alegia. Altunaren 1987: 4 arabera, (la)-ko bere-an indartua erabiltzeko arrazoia subjektuari dagokiola da. (1a)-ko haren, ordea, subjektua ez denari dagokio. Haren analisian, beraz, funtsean ez legoke legearen hausturarik (Altunak, noski, ez du LA legea aztergai nagusi, eta hortaz ez da LA legearen formulazio hertsi baten ni bezain gatibu). Aitzitik, Rebuschiren 1995: 343 arabera i. > n. aldaketaren arrazoia, kasu honetan, honakoa da: LVP osoan, subjektuak diren IS guztietako genitibozko izenordainak forma neutroan agertzen dira.

Rebuschiren planteamendu hau \$4.2-n eta §4.6-n aztertuko da xeheki. Esan dezadan, behin-behinik, primeran azaltzen dituela, dauden 6 hausturetarik 2 (3, hau ere sartzen badugu), eta, klausula bat gehiturik, ez duela kontraadibiderik. Are gehiago, bokatibozko sintagmetako genitibozko izenordainak sartzen badira jokoan, beste 3 haustura azal litzake (nahiz haustura hauek ez diren halakotzat jo 1. eta 2. tauletan; ikus bedi §4.6-n zergatik).

Zuzentzat jotzen dut, beraz, Rebuschiren araua. Behintzat (2b) azaltzeko bide bakarra deritzot, eta (2a) ere primeran argitzen du (baina ikus \$4.3). Hedatu ahal da, beraz, (1a)ra? Baliteke, baina gomendagarria da kontuan hartzea 3. pertsonan 1. eta 2. pertsonetan baino faktore gehiago sar daitezkeela jokoan. (1a)-n, haren zerbitzari xipiak subjektuaz landa behintzat hiru gauza gertatzen dira ${ }^{6}$. Lehenik, haren-en erreferentziakidea den datibozko IS ez da ageriki agertzen. Bigarrenik, agertuko balitz genitibozko izenordaina dagoen IS-ren ondoren agertuko litzateke, eta baita isilean gorde den aditza ere. Gehitu beharrekoa batueraz jarririk, isilean geratu den perpausa haren- ${ }_{i}$ zerbitzari xipiak dedikatzen dio Bernard Leheteri... edo litzateke. Hirugarrenik, aurreko guztiari gehitu behar diogu Bernard Leheteri aurreko perpausean aipatu berri dela.

Ez dakit hauetako faktoreren —edo faktore konbinazioren — batek eraginik duen bere > haren aldaketan, edo Rebuschiren araua nahikoa den aldaketa azaltzeko. Bestela planteaturik: mantenduko al zukeen haren Etxeparek beste perpaus honetan: Bernard Leheteri ${ }_{-i}$ dedikatzen

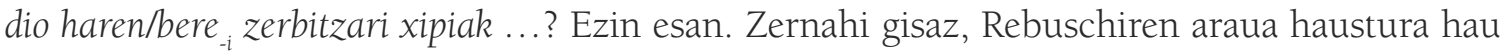
azaltzeko nahikoa dela egiaztatzeko, beste kasuren bat eskertzekoa litzateke, baina hau da Etxepareren lan osoan gertatzen den bakarra.

4.2. i. > n. subjektuak diren ISetan, eta ene/neure burua

Azpiatal honetan 1. p. sg.ean gertatzen diren eta benetakotzat jo ditudan hausturak

6. Gainera, ez da hutsala izango markatzea Iparraldeko autoreen geroztiko garapenean 3. pertsonetan LA legea sendo mantendu dela, 3. p.ko genitibozko izenordainei subjektuetan izateak ez diela erasan. 
iruzkinduko ditut. Lehenengo biak honakoak dira:

(2) a. en' etsaiak benzi enazan neure azken finian.

b. ene buruia ziaidazu harendako abastu.

(VII, 14)

Altunak 1987: 23 (2a)-ko ene bihurkaria izan arren neutroa delako egitatea egiaztatzen $\mathrm{du}$, besterik gabe, bigarrenean honelako testuinguru batean esperogarria den forma bai topatzen dugula ohartarazirik. (2b)-ko ene-az ere gauza bera dio (ikus 1987: 162), neure espero genukeela alegia. Rebuschiren 1995: 343, 347 arabera, ordea, arrazoia gorago aipatu dudana da bi kasuetan: ISk subjektuak direnez, haien genitibozko izenordain indartuak neutro bihurtzen dira.

Rebuschiren araua (2a-b)-n gehi, agian, (1a)-n, betetzen da, \$4.1-en aipatu ditugun arazoak gorabehera. Rebuschik berak 1995: 344 (3a) kontraadibidea eztabaidaratzen du.

(3) arrobatu nuzu eta balia bekit neuria".

(IX, 12)

Hau azaltzeko, frantziar euskalariak iradokitzen du honelako egiturotan hala Etxeparegan nola Iparraldeko gainerako autore zaharrengan benetako subjektua datiboan dagoen IS dela, absolutiboan dagoena subjektua ez baizik eta aditzaren osagarria delarik. Axularren, Etxeberri Ziburukoaren eta Leizarragaren adibideez hornitzen du argudiaketa hau. Nago, ordea, kontraadibide hau era sinpleago batean azal daitekeela Rebuschiren arauari ("subjektuak diren ISetan genitibozko izenordainen aldaera indartuak neutro bihurtzen dira") honako klausula hau gehitzen badiogu: “..., aditzaren ondoren agertu ezik". Sinpleago izateaz gain, klausula honek kontraesan bat saihesten laguntzen dio Rebuschiri. Izan ere, honek 1995: 344 dio "that ONB [= Old Northern Basque] allowed dative subjects associated with an absolutive complement". Baina, zer esan nahi du "allowed" horrek? Noiz bai eta noiz ez? Zergatik ezin dakioke aplikatu planteamendu hori (2b)-ri (zeinen subjektua niri litzatekeen, eta ene buruia aditzaren osagarria), horrela bertan neure buruia espero genukeelarik?

Ez dut beste kontraadibiderik topatu ${ }^{7}$, eta klausula hau onarturik Rebuschiren arauak era asebetegarri eta dotore batean (2a-b) eta agian (1a)-ko hausturak azaltzen dituela baiezta daiteke, ene iritziz.

\subsection{EBZetik jasotako neure-neure > ene-neure motako disimilazio morfologikorik?}

7. Rebuschik aipatzen ez duen bat honakoa izan liteke: Zuri gomendatzen nuzu hila eta bizia, / neure gorputz eta arima eta dudan guzia; (I, 421-422), baldin eta bigarren bertsoa ni isileko baten aposizio gisa interpretatzen badugu (hila eta bizia aposizioa den modu berean). Hau bat letorke Rebuschiren arauari gehitu diodan klausularekin. Hala ere, sinpleago da lehen bertsotik bigarrenera gomendatzen aditzaren diatesiaren aldaketa bat-edo gertatu dela onartzea: bihurkaria (morfologikoki iragangaitza) izatetik iragankorra izatera igarotzen da. Honen arabera, neure gorputza eta arima eta dudan guzia osagarri zuzena litzateke. Aquesolok 1978: 85 adizlagun bezala itzultzen du: "A Vos me encomiendo en muerte y en vida, / Con mi cuerpo y alma y con cuanto tengo". 
Salbuespenekin jarraitu aurretik, (2a)-ri buruzko hausnarketa bat egin nahi nuke. Martínez Areta 2015: 465-467-n Lazarragaren honako agerpena aztertu nuen:

Ene semea-ren ordez, neure semea espero genukeela nabarmena da. Bestetik, Lazarragaren testu osoan neure 53 aldiz ageri da espero dugun testuinguru batean, neure $>$ ene 3 bider baino agertzen ez delarik. Neure > ene hiru kasu hauetarik, bat 'X-gaz/ekin $\mathrm{Y}=\mathrm{X}$ eta Y' egitura koordinaziozko batean ageri da (A5: 25-26). Beste batean, neure > ene berau dagoen IS perpaus luze eta konplexu baten hasierara eramatearen ondorio da, horrela mintzagai bihurtuz ([Ene berbaok,] ... ze daidizu pensadu / [.. nik ditudala fingidu.]; A6: 3942). Azkena (4) da. Are gehiago, (4) Lazarragaren testu osoko kasu bakarra da, zeinetan, LA legea zurrunki bete baledi, perpaus berean 1. edo 2. pertsonako genitibozko izenordainaren aldaera indartua birritan agertuko litzatekeen. Horrela, planteatzen nuen ez ote zen hau EBZetik jasotako arkaismo baten aztarna bat, zeinen arabera perpaus berean bi neure, edo orokorrean 1. edo 2. pertsonako bi genitibozko izenordain indartu (hots, neure-neure, heure-heure, geure-geure, zeure-zeure, zeuen-zeuen) agertuz gero, lehenengoak "disimilazio morfologiko" bat jasango zuen, eta neutro bihurtuko (neure-neure > ene-neure, heure-heure > hire-heure, etab.). ${ }^{8}$

Ez nintzen jakitun, ordea, Etxepareren LVP-an gertatzen denaz. Arakatu dudanaren arabera, LVP osoan LA legea zurrunki bete baledi, perpaus berean 1. edo 2. pertsonako genitibozko izenordainaren aldaera indartua birritan agertuko litzatekeen leku bakarra goiko (2a) da, eta, kasualitatez, neure-neure sekuentzia honetan lehena ene bihurtzen da. Baina diot ene "bihurtzen" dela, ez disimilatzen, eta bestetik ez diot kasualitatez-i komatxo ironikorik

8. Han esandakoari (ikus 2015: 465-467) bi zehaztapen txiki egin nahi nizkioke. Batetik, A6: 39 42-ko neure > ene aldaketa neure-neure > ene-neure-ko beste kasu bat izan zitekeela iradokitzen nuen. Honek esan nahiko luke kasuak, zeinetan 1. eta 2, p.ko bi genitibozko forma indarturen talka posible den, bi direla (ez bakarrik bat), eta bietan gauzatuko litzateke disimilazio morfologikoa. Hala ere, ustezko disimilazio morfologikoaren formulazio hertsiarekin ez letorke bat. Perpaus osoa honakoa da: [Ene berbaok,] jente noblea, / ze daidizu pensadu / [ $[$ eure erria alabatzerren] / nik ditudala fingidu.] Etzanetan ez dauden kortxeteak bata bestearen jarraipen ditugu, eta hortaz perpaus etena, baina bakarra, islatzen dute. Hala ere, bigarren neure-a aldi berean beste menpeko perpaus batean txertatuta dago. Hortaz, ene/neure-ak ez ditugu zehazki perpaus berean (hots, esparru sintaktiko berean eta aditz berberaren menpekotasunean), eta hau ez da neure-neure > ene-neure (ustezko) prozesuaren kasu bat, behintzat prozesuaren formulazioa zabaltzen ez dugun bitartean. Bestetik, (4)-rako neure > ene aldaketaren atzean neurkerari lotutako faktorerik egon ez ote zitekeen planteatzen nuen (hau iradokitako neure-neure > ene-neure prozesuaren aurka bazihoan ere), neure-k ez bezala ene-k arrezkero-rekiko sinalefa ahalbidetzen duen bitartean, lehen hemistikioa 8 silabako bihurtuz. Baina, neurkera kontutan aditua izan gabe, eta Lazarragaren neurkeraren ikerketaren baten zain, esango nuke aurreko eta ondorengo bertsoei so bat nahikoa dela pasarte horretako bertso gehienak 4 / 4 // 4 / 4 irakurri behar direla, eta hortaz ene eta neure-ren arteko hautapenak ez duela neurkerarekin inongo zerikusirik: arrezkero / ene neure semea // ..., semea-k sineresia jasaten duela. 
jartzen, §4.2-n onartu dudanaren arabera hala baita, kasualitate bat. Hau da, §4.2-n onartu dut (2b), eta agian (1a), azaltzeko era bakarra Rebuschiren araua onartzea dela, beroni klausula bat gehitu badiogu ere. (2a) modu berean interpreta daiteke. Baztertzen al du honek EBZetik jasotako neure-neure > ene-neure disimilazio morfologiko bat hala Lazarragagan nola Etxeparegan oraindik indarrean zegoelako hipotesia? Ez, baina jukutria gaiztoa egiten dio, haren egiaztapena Etxeparegan eragozten baitu. Marka bedi: ez dakigu neure-neure > ene-neure ustezko lege arkaiko bat EBZetik Etxepareren LVP-ra bizirik iraun duen, baina, egin balu, legea egiazta lezakeen LVP-ak dakarren kasu bakarrean Rebuschiren arauak ("subjektuak diren ISetan genitibozko izenordainen aldaera indartuak neutro bihurtzen dira, aditzaren ondoren agertu ezik") lehen neure-a edozein kasutan ene bihurtuko luke. Ez dakigu, beraz, Rebuschiren arauaren aurretik neure-neure > ene-neure bat aplikatu den. Horretarako, jakin beharko genuke nola esango lukeen Etxeparek, adibidez, Lazarragaren (4) (bertan, jatorrizko lehen neure-a osagarri zuzena den IS batean dago, eta Rebuschiren arauak ez luke ene bihurtuko).

Egiari zor, beraz, (4) ez da Martínez Aretan 2015: 465-467 iradokitako legearen (zehazkiago, Linschmann-Aresti legearen azpilegearen) aldeko zantzu bat, itxurak itxura. Aitortu behar dut ez dela hau azpilege honen aldeko aztarnarik aurkitu nahi (agian setati samarr)ak bilaketaren amaieran sentipen mingotsa uzten didan lehen aldia, hasiera batean etorkizun handiko paralelo bat ematen duena, datuen miaketa xehe baten ondoren ez delarik hipotesi sendo bihurtzeko bezain asebetegarria. Emozio handirik gabe -baina oraingoz behintzat etsiko ez dudala gaztigatuz-, aipa ditzadan hauetako aztarna batzuk.

(5) a. Enea neuretzat, / zurea bioenzat.

$(R S, 445)$

b. Amar Mandamentu oek daude Mandamentu bitan enzerraturik: Jaungoikoa amatzean, eta serbitzean gauza guzien gañean; eta geure proximoa geren buruak bezela serbitzean, eta amatzean. (Otx.A., DKE)

c. Bada uste duzu, [zure dirua edo hazienda zuk zeure ondokoari, [zeure zorraren eta obligazionearen pagatzeko] utzten diozuna,] etzaikala zure ondoko hari ere zuri bezain on, gozo eta eder idurituko?

(5a) RS-en kasu bakarra da non, LA legea zurrunki bete baledi, 1. edo 2. pertsonako bi genitibozko izenordain indartu izango genituzkeen perpaus berean. Hala ere, hemen neureneure > ene-neure gertatu delako interpretazioak isileko aditza dot, eta ez da, dela onartzea eskatuko luke.

(5b) -k badu interesik, aztergai dugun azpilegearen kontuaz haraindi. Berriki Borja Ariztimuñok ohartarazi dit (eta argitaratzear du Ariztimuño 2015-en) Otxoa Arin-en PaterNoster-ean oso gertakari deigarri bat nabari dela 1. p. pl.arekin, zeina, pasarte berbera jorratu zuen Sarasolaren 1980: 439 analisian deskribatutakoa ("argi bide dago Ordiziko idazleak ez duela bereizkuntza egiten eta erabiltzen dituen formak bigarren erakoak direla") baino konplexuxeago baita. Ondo arakatuz gero, honakoa antzeman diezaiokegu pasarte honi: gure desagertu da, baina haren leku sintaktikoa geure-k okupatu du. Beronen lekua, ordea, 2. p. pl.aren eraginpeko berrikuntza morfologikoak diren geren eta geuren aldaerek beretu dute. Horrek esan nahi du LA legea bizirik dirauela 1. p. pl.ean, baina forma morfologikoen korrimendu batekin batera. Ariztimuñoren analisiari jarraikiz, nire analisiaren eta zenbaketaren arabera, gere/geure aldaera neutrotzat harturik Doktrina osoan LA legea 22 kasutan betetzen 
da (lan honetan erabiltzen ari naizen irizpide berekin), eta 9tan $e z^{9}$ (badira 3 gure ere, neutro gisa jokatzen dutenak). Bestetik, geren/geuren aldaera indartutzat harturik, legea 18 kasutan betetzen da, eta bakar lean ez. Bada —eta hona iritsi nahi nuen gaurkoz, Otxoa Arinen azterketa osoago bat aurreragorako utziaz-, aldaera neutroen 22/9 proportzioaren 9 kasuetako bat (5b) da (testuinguru osoa ikus dadin lerrokada osoa kopiatu dut). Testu osoan ez dago LA legea beteaz bi ge(u)ren perpaus berean agertuko liratekeen beste kasurik. Markatu nahi nuke, gainera, Salbe Regina-raino, berau barne, Ariztimuñoren planteamenduak ez duela salbuespenik.

Azkenik, Martínez Areta 2015: 467-n Axularrengan eta Tartasengan behintzat azpilegea desagertua zela —inoiz existitu bazen — hiru adibideren bidez adierazten banuen ere, ez dago sobera (5c) eztabaidaratzea, haren zeure > zure-ren arrazoia bestelakoa izan litekeen arren (adibidez, zure dirua edo hazienda subjektuaren aurretik dela kontuan harturik, ezker aldeko destokitze bat; ikus Martínez Areta 2015: 465-466, honen inguruan).

Gertakari hauek guztiok kasualitate hutsak, garapen burujabeak, edo espejismoak dirateke, zalantzarik ez, baina (autore bakar batentzat izanagatik sendoa den) Ariztimuñorena bezalako oharpenek agerian uzten dute orain arte LA legeari eman zaion arreta eskasa.

\subsection{Azalpen zaileko bi haustura: VII, 28 eta XIII, 34}

Itzul gaitezen LVP-ra. VII, 28-ko eta XIII, 34-ko hausturak azpisail berean elkartu ditut, aditz jokatuko perpausetako i. > n. hausturen agerreraren hurrenkeran hurrengoak direlako batetik, eta bestetik biak elkartzen dituelako azalpen zailekoak izateak.

(6) a. Iaungoikoa, edetazu amoria gogotik eta haren irudia ene begietarik

b. nik eniak badakuskit ene gaitzaz bozturik,

(6a) -n, ene begietarik menpe duen aditza edetazu da, eta hortaz neure esperoko genuke. Altunak 1987: 166 galdetzen du: "[e]z ote da eta-k abia ematen dion perpausean bertan adizkirik ez delako?" Alabaina, hala berak nola Rebuschik 1995: 346 egitura beretsuko Ioan daraudazu lehen bihotza, / gero gatibatu neure gorputza (X, 33-34)-rekin erkatzen dute. Eta bertan neure mantentzen da. Azalpen ilunekotzat joko dugu, beraz. Ohartarazi nahi dut (6a) neure > ene aldaketako kasu bakarra —izan ere, legearen haustura bakarra - dela, zeinetan genitibozko izenordaina aditzaren ondoren agertzen den. Bestetik, neure > ene aldaketako (2b) eta (7) agerpenekin ezaugarri bat partekatzen du: genitibozko izenordaina datibozko argumentuaren erreferentziakidea izatea, alegia.

(6b) LVP osoko LA legearen hausturarik txundigarriena da. Hartan, (6a)-n ez bezala

9. Iruditu zait, hala ere, hauetako zenbaitzuk pasarte gutxi batzuetan pilatzen direla (4 adibide Lehen Kapituluko §I atalean), eta besteren baten haustura "menpekotasun-erakarpen" gisa-edo uler daitekeela, ondokoa kasu: Da [geure Aita Adanengandik heredatu genduan pekatua,] (4. Kap., §VII). 
genitibozko izenordaina aditzaren aurretik agertzen da, baina subjektu erreferentziakidea ezin gertuago du genitibozko izenordainak, eta justu aurretik! Altunak (1987: 236) iradokitzen du ez ote diren izango hala eniak nola ene menpeko perpausekoak, partizipioarenekoak hain zuzen, eta horrenbestez [eniak (...) ene gaitzaz bozturik] interpretatu behar. Baina, Rebuschik 1995: 346 osteratzen dion bezala, honek badakuskit-en pluraleko komunztadura azalpenik gabe uzten du.

Konbentzimendu handirik gabe, bururatzen zait eniak Wackernagel kokagunean ezarririko mintzagai bat izan litekeela, eta horrela perpauseko sintaxitik at geratu. Hala balitz, Etxeparek buruan izango zukeen puntuaketa honakoa izango zen: nik, eniak, badakuskit, ene gaitzaz bozturik. Mintzagai batek i. > n. aldaketa eragitea, edozein kasutan, ez dauka paralelorik LVP osoan (paralelo posible bakarra VIII, 11 litzateke, eta \$2.2-n ikusi dugu beste azalpen hobeago bat duela).

\subsection{LA legea eta TOG-a}

Aurkitu dudan benetako azken haustura ez dute halakotzat aipatzen ez Altunak, ez Rebuschik. (7)-n dakusagu.

(7) heben ene penatzera zaidanian orhitu.

(XIII, 58)

Nire analisiaren arabera hau LA legearen urraketa bat dela, 1. p. sg.eko edo 3. p.ko genitibozko izenordain bat TOG batean txertaturik duten LVP-ko gainerako pasarteen erkaketa batek erakuts dezake:

(8) a. eta jinen direnek gero duten kausa oboro haren abanzatzeko, (Esk, 28-29)

b. Ene gaizki penatzeko hain ederrik sortu zen,

c. neure penen erraitera are eniz ausartzen.

d. ene gaizki penatzeko segur sorthu zinaden

e. neure gaizki penatzeko har zinzadan amore;

f. ene gaizki egitiaz enek laido lukeite;

Ohar bedi gaizki penatu aditz bateratu gisa aztertu behar dela. Hori gogoan, (8a, b, d, f) eta (8e) erkatzen baditugu, ikus dezakegu aditz-izenaren zuzeneko osagarri zuzena genitibozko izenordaina bera baldin bada, orduan beronen kontrolatzailea ez dela TOG-a baimentzen duen aditz jokatugabea, berau kokaturik dagoen perpauseko aditza baizik. Bada, aditz horretan aldaera indartua baimen dezakeen marka bat dakarren bakarra (8e) dugu. Haatik, arau honen arabera (7)-n ere aldaera indartua esperoko genuke.

Esango nuke, beraz, jokamolde zaharra (8e)-koa dela. Egiazki, oso bitxia litzateke hau berrikuntzatzat jotzea, hausturetako kasu guztiak kontrako norabidean (neure $>$ ene) doazelarik. Badirudi, bestetik, 1. eta 2. pertsonetan aldaera indartuen desagerpenerantz doazen Iparraldeko hizkeretan testuinguru konkretu batzuk zedarri hartzen direla aldaera neutroen orokorpenerako. Hauetako testuinguru bat, hain zuzen, TOG-a baimentzen duen aditz jokatugabe baten berehalako osagarri zuzeneko kokagunea da. Printzipioz LA legearekin gordetzaileago den Axularrek berak aldaera neutroen aldeko orokorpenaren zantzuak agertzen 
ditu honelako testuinguruan. (9a, b, c) dira nik aurkitu ditudan tankera honetako guztiak.

(9) a. Zahartasuneko pairua eta pairatzea, ezina da eta ez pairua eta ez pairatzea: (...); ez guk bekhatuen, baiña bekhatuak gure utztea.

(Ax, Gero 119)

b. eta hautsten dio Iainkoari bihotza, eta emaiten okhasino zure faboratzeko.

(Ax, Gero 147)

c. Eta hala erran ahal dezakegu ezen (...), badugula halaber gaixto bat ere, bere ahalaz gure tentatzeko;

(Ax, Gero 356)

Aipaturiko irizpidearen arabera (9a, b) esperogarriak diren bitartean, (9c)-n geure esperoko genuke.

\subsection{LA legea bokatibozko ISetan}

Bokatibozko ISetan, Etxeparek gehienbat aldaera neutroa darabil, testuingurua zeinnahi ere den, eta horregatik LA legea betetzen den kasuen artean (hots, n. zutabean) sartu ditut aldaera neutroa duten agerpenak. 1. eta 2. tauletan bokatiboak aditz isileko perpausekin batera sartu ditut. Berez bokatiboak diren kasuak honakoak dira bakarrik: 2. p. sg.ean, n.-ko agerpen bakar bat (II, 64); 1. p. sg.ean, n.-ko 6 agerpen (I, 369; VI, 11; VII, 1; IX, 3; X, 7; XII, 38), eta, azkenik, n. >i.-ko 2 agerpen. Azken biotan, beraz, harturiko irizpidearen arabera LA legea hausten da, baina aipaturiko arrazoiengatik hauek ez dira benetako hausturak. Zernahi gisaz, honakoak dira:

(10) a. ordu hartan hel zakitzat, othoi, ama eztia, ararteko leial eta neure aiutaria.

b. - "Bada, neure maitia, nik diotsut egia:

Rebuschik 1995: 345-346, hala ere, bokatibozko sintagmen beste analisi bat egiten du, bere arauarekin ("subjektuak diren IS guztietako genitibozko izenordainak forma neutroan agertuko dira") lotu nahian. Horrela, (10b) ondoko (11)-rekin erkatzen du.

(11) Ene maite maitena, egidazu zuzena;

Hurrenez hurreneko bokatibozko sintagmak ez du argumentua bera ordezkatzen ez (10b)-n ez (11)-n, horretarako neure maitia-k datiboan agertu beharko bailuke, eta ene maite maitena-k ergatiboan. Baina Rebuschik diosku: "Let us, admit, however, that the vocative NP can somehow inherit the coindexation properties of the argument it corresponds to; the two occurrences would then be regular, since we have seen that the genitives in subject NPs never show up in the strong form in Etxepare". Nik n.-tzat hartu ditudan honako bi agerpenok haren 
planteamenduaren alde dihardute ${ }^{10}$ :

(12) a. Elas, amoros gaixoa, hire enganatuia, erhogoatan badaramak eure mende guzia!

b. Elas, ene amoria, nola nuzun penatzen,

Haren alde jardun arren, (12b)-ri ere ez omen zion erreparatu. Goiko (10a) ere ez dago berak dakartzan agerpenen artean, eta hartan printzipioz haren araua ez da betetzen. Rebuschik esan lezake, hau azaltzeko, absolutiboan dagoena aditzaren osagarri dela (ikus §4.2), ez subjektua. Baina nik Rebuschiren arauari ezarri diodan klausulak (“..., aditzaren ondoren agertu ezik") ere (10a) azaltzen du, beti Rebuschiren beraren planteamendu honen barnean.

Markagarria da, bokatibozko sintagmak albo batera utzita, subjektuak diren ISetako genitibozko izenordainetan i. > n. aldaketa aurresaten duen Rebischiren araua testu osoan hiru bider (hots, (1a), (2a, b)) bakarrik betetzen dela (kontraadibiderik gabe, nik ezarritako klausula aintzat harturik), baina planteamendu bera bokatibozko sintagmetara zabaltzen badugu, gainerako testuan bezainbeste bider (hots, (11), (12a, b)) dugula i. > n. subjektuetan, berriro ere kontraadibiderik gabe. Ez dakit honek Rebuschiren arauaren baliotasunaren alde, bokatibozko ISetan, hitz egingo duen. Baina bokatibozko sintagmen morfo-sintaxia berez labainkorra izanik, datuak tauletan sartzeko planteamendurik kontzerbatzaileenetik (bokatibozko ISetan Etxeparek aldaera neutroak darabiltzalako hipotesistik, hain zuzen) abiatu naiz.

\section{Amaitzeko}

Laburbilduz, esan dezadan Etxepareren LVP-an printzipioz LA legeak 3. pertsonekin, 1. p. sg.arekin eta lagunarteko tratamenduko 2. p. sg.arekin mantentzen den arren, legearen benetako 6 haustura topatu ditudala (bokatibozko sintagmetakoak albo batera utzita), denak i. > n. norabidean. Hauetarik, 5 1. p. sg.ean gertatzen dira, eta 3 subjektuak diren ISen barnean. Azken hiru kasuok Rebuschiren arauaren bidez azal daitezke ("subjektuak diren ISetan genitibozko izenordainen aldaera indartuak neutro bihurtzen dira"), zeinak ez daukan salbuespenik honako klausula gehitzen badiogu: "..., aditzaren ondoren agertu ezik". Gainontzeko 3etarik, bat TOG-a baimentzen duen aditz jokatugabe baten berehalako osagarri zuzeneko kokagunean zabaltzen ari den aldaera neutroen orokorpenaren erakusgarri izan daiteke. Beste biak (6a, b) arras zailak dira ezein kategorizaziotan sartzen.

Hortaz, Rebuschik 1995: 346 arrazoi du euskaraz inprimaturiko lehen liburuan ene aldaera neutroa neure aldaera indartuari eremua kentzen hasita zegoela dioenean. Ziur aski, lagunarteko tratamenduko 2. p. sg.ean gauza bera gertatzen ari zen, baina pertsona honekin

10. Eta, jakina, bokatibozko sintagma perpauseko sintaxi arruntean sartuz gero, orduan $(h)$ eure- $(h$ eure $>$ hire-(h)eure disimilazio morfologikoaren beste kasu bat izango genuke. Baina, (2a)-n bezala,Rebuschiren arauak eragotziko luke hau EBZetik jasotako ezaugarria den egiaztatzea. 
datuak urriago dira, eta urraketarik ezak hauek zein bidetatik zihoazen jakitea eragozten digu.

Orokorkiago, esan dezakegu Iparraldean gertatzen den LA legearen desegitea prozesu dinamiko bat dela. Garapena eta/edo banaketa geografikoa era eroso eta didaktiko batean azaltzeko, usu zenbait zedarri bereizten ditugu. Horrela, lapurtera klasikoko autoreek bereziki Axularrek eta Etxeberri Ziburukoak- zazpi pertsonetan betetzen dute legea, era sistematikoa batean. Leizarragagan eta Etxeparegan, ordea, gure/geure, zure/zeure eta zuen/ zeuen oposaketetan aldaera indartuak desagertu dira, baina bestela LA legea bizirik dirau. XVIII. mende erdiko Kadet \& Bettiriño-n, hire/(h)eure bikotean ere indartua desagertu da, eta oposaketa 1. p. sg.era eta 3. pertsonetara murriztua geratu da, Padillak 2011: 83-85 deskribatu legez. Azkenik, nafar-lapurteraz legeak 3. pertsonekin baino ez dirau bizirik. Alabaina, zedarriok ez dira konpartimentu estankoak. Tarteko pauso batzuetan bi aldaerak aldakortasun librean egon daitezke, Harizmendi eta Argainaratsi buruzko iruzkinetan Rebuschik 1995: 331-332 markatu zuen moduan. Egoera sinkroniko batean legeak dagoen fasean tinkoa dirudienean ere, salbuespenak eta pitzadurak agertzen ditu (usu zeharo erregulartzat jotzen den Axularrekin hasita), eta, miaketa xehe baten ondoren, pitzadurok ez ohi dira zorizkoak, hurrengo garapenaren adierazgarri baizik, Iparraldean beti dena oposaketa baten aldaera indartuaren desagerpena.

\section{Erreferentziak}

Altuna, Patxi. 1987. Linguae Vasconum Primitiae (edizio kritikoa). Bilbo: Euskaltzaindia.

Aquesolo, Lino. 1978. Olerkiak. Bernat Dechepare. 1545. Donostia: Txertoa.

Ariztimuño, Borja. 2015. Euskararen dialekto zaharrak aztertzeko saioa: aitagureen mithridates baten deskribapena (prentsan).

Martínez Areta, Mikel. 2015. Linschmann-Aresti legea Lazarragaren testuan. In Beatriz Fernández \& Pello Salaburu (arg.), Ibon Sarasola, gorazarre. 457-472. Bilbao: Euskal Herriko Unibertsitatea.

Mounole, Céline. 2015. Datibo-komunztaduraz eta laguntzaile hirupertsonalen diakroniaz. In Beatriz Fernández \& Pello Salaburu (arg.), Ibon Sarasola, gorazarre. 473-490. Bilbao: Euskal Herriko Unibertsitatea.

Padilla, Manuel. 2011. Kadet eta Bettiriño (edizio kritikoa). Bilbo: Euskaltzaindia.

Rebuschi, George. 1995. Weak and Strong Genitive Pronouns in Northern Basque: A dichronic perspective. In José Ignacio Hualde \& Joseba Andoni Lakarra \& Roger Larry Trask (arg.), Towards a History of the Basque Language. 313-356. Amsterdam \& Philadelphia: John Benjamins.

Sarasola, Ibon. 1980. Nire/neure, zure/zeure literatur tradizioan. Euskera 25. 431-446. 